\title{
Modification of plaster compositions for building facade finishing with nanotechnological materials
}

\author{
Anna Pershina ${ }^{1, *}$, Alla Ponomarenko ${ }^{1}$ and Elvira Borodacheva ${ }^{1}$ \\ ${ }^{1}$ Samara State Technical University, Institute of Architecture and Civil Engineering, 194, \\ Molodogvardeyskaya St., 443001, Samara, Russia
}

\begin{abstract}
Analysis of the modern state of the facade system market was conducted, major deficiencies and basic requirements to facade surfaces and materials were identified. It was established that high quality of the surfaces is achieved through stability of the composition and properties of the raw materials used, and fillers - their quantitative content and dispersity - play a particularly important role. The problem of the optimal filling of plaster compositions, labor intensity and low profitability of natural filler production was raised A solution was suggested: expand the nomenclature of fillers for plaster compositions of the new generation, apply nanotechnological raw materials, in particular, carbonate sludge - the product of reactant treatment of waste water from thermal power plants and carbonate siliceous product flue dust from asphalt concrete plants. Both wastes are depositable anthropogenic sources of environmental pollution. Formulations of facade compositions, modified with nanotechnological mineral fillers with high properties (adhesive strength, compressive strength, cold resistance), confirmed by a number of Russian patents, have been developed.
\end{abstract}

\section{Introduction}

Building facades are a mosaic that forms the face of any city. However, exterior building envelopes are daily exposed to adverse environmental factors: atmospheric precipitation (rain, snow, hail), wind, thermal and mechanical stress, ultraviolet and gamma rays, chemically active airborne substances, which often cause numerous sorts of decay and deformations at different stages of building maintenance.

In Russia, the system with a thin plaster layer has become one of the most favored options for the finishing of building facades due to the following main advantages:

- well-balanced response of a plastered system to deformation caused by abrupt temperature fluctuations;

- sufficient vapor permeability of the materials employed, which protects the wall construction from excessive moistening;

\footnotetext{
*Corresponding author: mironova163@mail.ru
} 
- protection of the wall base material from exposure to carbon dioxide, water and other aggressive agents, thus preventing chemical degradation and corrosion of the wall structure;

- reducing costs of the foundation construction due to the relatively light weight of the exterior envelope coating;

- avoiding efflorescence on the facade surface;

- solution to the problem of interpanel joints in panel buildings;

- improved sound insulation of exterior walls;

- wide applicability both in newly constructed buildings and in the refurbishment of existing buildings, with a wide color palette of the façade finish;

Still, the system has its own specific features, in particular, a number of drawbacks and limitations:

- installation works have to be carried out with accuracy and precision: strict adherence to the proportions of all components when preparing the solution is required; prepared composition has to be used within 2 hours;

- can be applied to buildings up to $75 \mathrm{~m}$ in height ( 25 floors);

- due to natural and climatic conditions:

- allowed wind pressure according to the design specification 20.13330.2011 Loads and impacts;

- allowed design ambient air temperature in winter is not below $-40^{\circ} \mathrm{C}$ (average temperature of the coldest five-day period);

- allowed humidity areas according to the design specification 50.13330. 2012 Building heat insulation - dry, normal;

- allowed aggressiveness degree of the outdoor environment - non-aggressive, mildly aggressive.

Modern development trends of the construction industry in the field of facade coatings require highly efficient front surfaces of the building walls, which can be achieved through:

- feasibility of architectural and aesthetic solutions;

- rational use of labor, natural, technological and material resources;

- implementation of innovative composition solutions that meet construction norms and standards;

- high performance characteristics and durability of building coatings.

\section{Materials and methods}

Selection of facade plaster compositions was made, best compositions were identified, tests were carried out in accordance with GOST 31356-2007, design specification 82-10-98, GOST 5802-86, GOST 28013-98, at the scientific laboratory of the Construction Materials department of the Institute of Architecture and Civil Engineering, Samara State Technical University. Modern physical and chemical methods for research and measurement were applied in the work: mictostructures (EVM-100 BR electronic microscope), identification of the adsorption capacity of the solution components GOST 21283-93 (Spectrophotometer KFK-3-01-ZOMZ), differential thermal analysis (derivatograph Q-1500 D) and X-ray phase analysis (diffractometer DRON-2).

\section{Results}

Among sludges, a particular attention should be given to carbonate sludges (CS) from water softening at thermal power plants (TPP), with a particle size of 20-60 nm, and carbonate siliceous product (CSP) - flue dust generated in the production of road construction mixtures at asphalt concrete plants (ACP), with a particle size of 60-80 nm. The particle 
size of industrial wastes has been measured by the low-angle neutron scattering method (LANSM) at B.P. Konstantinov St. Petersburg Nuclear Physics Institute. Chemical composition of nanotechnological raw materials is provided in table 1 [1].

Table 1. The chemical composition and the particle size nanotechnological raw materials.

\begin{tabular}{|c|c|c|c|c|c|c|c|c|c|}
\hline \multirow{2}{*}{ Waste } & \multicolumn{7}{|c|}{ Oxides content, \% by weight } & \multirow{2}{*}{$\begin{array}{c}\text { Particle } \\
\text { size, nm }\end{array}$} \\
\cline { 2 - 10 } & $\begin{array}{c}\text { Loss on } \\
\text { ignition }\end{array}$ & $\mathrm{SiO}_{2}$ & $\mathrm{Al}_{2} \mathrm{O}_{3}$ & $\mathrm{Fe}_{2} \mathrm{O}_{3}$ & $\mathrm{CaO}$ & $\mathrm{MgO}$ & $\mathrm{SO}_{3}$ & $\mathrm{R}_{2} \mathrm{O}$ & $20-60$ \\
\hline $\begin{array}{c}\text { Carbonate } \\
\text { sludge }\end{array}$ & 34 & 2 & 5 & 7 & 41 & 8 & 3 & - & 20 \\
\hline $\begin{array}{c}\text { Carbonate } \\
\text { siliceous } \\
\text { product }\end{array}$ & 39 & 11 & - & 3 & 34 & 12 & 1 & - & $60-80$ \\
\hline
\end{tabular}

The optimal CS amount in the wet state was $5 \%$ of the binder mass, in the dry state $15 \%$, CSP amount $-13 \%$ of the total composition mass. As the result of the scientific work with the use of CS and CSP as a binder, both separately and as cluster-forming binary systems, the following advantages of the materials received were obtained [2-5]:

- higher adhesion: solvation shells of sludge particles help provide conditions for their mobility, which supports formation of dimensional contacts in the mixture. Conditions of the CSP production influence formation of the rough surface, which ensures development of sufficient number of active centers and a clear demonstration of adhesion forces $[6,7]$;

- increased cold resistance and compressive strength due to easy distribution of nanoparticles in the cement and polymer matrix, resulting in highly filled compositions; Introduction of CS and CSP as a binary system in the solution mixture allowed to enhance the properties modifying the pore space;

- enhanced plasticity and remoldability of the mixture due to the presence of adsorptionbound water in CS that facilitates sliding and prevents coagulation of nano-particles. CSP can also improve remoldability due to the nano-size;

Based on the works by M. M. Sychev, V. I. Solomatov, A. N. Bobrushev, A. N. Proshin, P. A. Rebinder, it is apparent that structure-forming participation and modifying influence of nanotechnological wastes on facade multicomponent plaster compositions result from the following interconnected mechanisms [8-10]:

- chemical mechanism of nano-size particles participation in heterogeneous processes of phase formation in hydrated compounds which may be defined by the chemical and mineralogical composition of the particles and the surface energy. Strength of cohesion crystallization contact of the hardened glue joint is likely to be a function of the chemical interaction mechanism in the contact area;

- catalytic mechanism of the nano-size particles as crystallization centers. Nano-disperse particles serve as crystal seeds;

- zoning mechanism of the hardening structure of the nano-size particles. Forming crystals grow epitaxially on the surface, increasing the contact density of the surfaces glued together;

- mechanism of the action of molecular forces due to the presence of water and formation of the chain of oriented dipole molecules of dissolved adhesive agent and solvent. Adsorption layer that initiates molecule polarization is the beginning of the chain;

- mechanism that provides for enhanced density of the system packing. High filling of the composition is provided by the nano-size of industrial wastes used which enables them to easily distribute in the binder matrix;

- strengthening mechanism of the contact area, resulting from complex physical and chemical processes that lead to formation of crystals with a higher activity than when only cement without nano-particles is used, in the cement-sludge system. 


\section{Discussion}

Modern plaster mixtures - multicomponent compositions, consisting of mineral binder, aggregate, filler, polymer dispersion and multifunctional chemical additives, providing the mixture with the necessary rheological properties that control the setting rate and ensure the adequate physical and mechanical properties of the solution after it develops the strength. Fillers are the main component of many plaster compositions. Fillers are intended to ensure excellent sticking capacity due to enhanced adhesive and cohesive properties [11].

Construction industry offers a huge variety of fillers with the following basic properties:

- hydrophobic property, i.e. the ability of finely dispersed mineral particles to repel water solutions;

- lyophilic property, i.e. the ability of particles, pretreated with surface active agents (SAA), to develop a hydrophobic reaction with oils. Mineral particles treated with SAA have a low interfacial tension and surface resistance to coagulation;

- sedimentation stability, i.e. capacity of the system for even distribution in the whole volume of the system, without breaking down into fractions of different density, and to resist the action of gravity. This is facilitated by a sufficient lyophilic property of the mineral particles that actively interact as they are moistened by liquids and swell;

- dispersing ability, i.e. capacity of mineral particles to break down into smaller parts from coagulative volumes when all system components are mixed.

Bearing in mind the foregoing, let us analyze and review a broad spectrum of widely used fillers [12-15]:

- dolomite - carbonate filler with a low content of contaminants, low yellowness and high whiteness, a hardness of 3.5-4 on the Mohs scale;

- barite concentrate and fractionated micro-barite have a high density, chemical and temperature resistance, capacity to trap gamma rays, a hardness of 3.5-4 on the Mohs scale; Barite concentrate serves as protection from harmful $\mathrm{x}$-rays in plaster mixtures. Microbarite has an effective granulometric composition, high whiteness; - wollastonite has a needle-like structure. The quality grade of this filler is determined by the length-to-width ratio of crystals that maintain their needle-like shape after grinding, which gives compositions additional reinforcing properties, resistance to deformation (shrink resistance) and abrasive load. Hardness on the Mohs scale is 1-2;

- mica minerals consist of crystals in the form of plates assembled in columns that give the mineral structure specific physical, mechanical and thermal capacity properties. With any grinding fineness of this material's particles, their plate shape is maintained. Hardness on the Mohs scale is 2-3;

- quartz powder - one of the strongest mineral fillers due to the structure of its crystalline lattice and hardness of 7 on the Mohs scale. When ground and milled, band composition of $\mathrm{SiO}_{2}$ tetrahedra in the quartz structure facilitates forming of elongated, angular particles. The main advantage of quartz is in its chemical and mechanical durability, electro- and thermal insulation properties;

- marble - it contains an increased amount of calcium carbonate, a low amount of coloring metal oxides and water-soluble salts, which make this filler resistant to ultraviolet rays. Crystalline structure of marble gives the composition good strength properties and low water adsorption. Hardness on the Mohs scale is 3. Hydrophobic marble is used for compositions with special requirements for humidity and lyophilic properties of fillers, sedimentation stability and enhanced dispersing ability in non-aqueous systems.

Hydrophobic marble grades - micro-calcite, calcium carbonate - have the following properties:

- high whiteness that retains optical and color characteristics even when treated with SAA; 
- low abrasiveness;

- high chemical purity - a minimum amount of foreign chemical compounds;

- good dispersive ability that provides for more highly filled compositions;

- capacity for $100 \%$ treatment of mineral particles with fatty acids (SAA), which make the surface hydrophobic, thus increasing compatibility of the filler with a polymer dispersion and reducing water adsorption. In presence of water, bonds on the marblepolymer phase boundary weaken, which is especially important for highly filled compositions where the strength of the interfacial layer defines the overall strength of the material, transferring a load from the polymer matrix on the filler;

- capacity to prevent adsorption of polar additives (antioxidants, antipyrens, stabilizers) by the filler when treated with SAA (fatty acids);

- capacity of the polymer dispersion to easily distribute in the matrix, reducing viscosity of the composition;

- capacity to enhance strength properties of the composition.

The process of choosing the coating often raises the issues that require rational and effective solution: minimizing costs on purchase, mounting and use of multilayer facade sandwich-like structure. These issues can be solved through the use of nanotechnological wastes as fillers in facade plaster compositions. The nomenclature can be expanded through the inclusion of numerous industrial wastes, in particular, sludges - residues resulting from reactant treatment in ferrous and nonferrous metal industry, as well as energy industry. Waste water of these industries is the most common source of sludge in Russia and abroad. The problem of sludge waste disposal in the Samara region occurred in the 1960-s due to the rapid growth of industrial production. At the same time, the regulations regarding the content of maximum allowable concentrations of harmful and toxic substances in waste water were tightened. Most large-tonnage sludges have no practical application, so their deposition is a source of anthropogenic environmental pollution.

The consequences of negative impact of sludge wastes of different hazard classes on the ecological balance and humans can be dealt with through application of such wastes as an alternative resource and modifier, so they will be efficiently disposed of in facade plaster compositions. Apparently, it is reasonable to use such a common industrial waste as sludge, having unique physical and chemical properties, with regard to environmental, economic and social aspects. Dozens of tons of water treatment and water softening wastes are annually generated at industrial facilities and thermal power plants (TPP) in the Samara region. Wet industrial wastes are products of chemical deposition when a solid phase precipitates from the water treatment system due to reactant treatment of water.

Thermal power plants often use standard lime treatment for water softening that produces wet wastes. The difference between sludge and sediment is in the former's constant composition, sedimentation and aggregative stability of its disperse structure. The process of turning sludge into a dense, deeply dehydrated product occurs when condensed industrial wastes are stored on sludge landfills and disposal sites, due to structural and phase transformations under the impact of ultraviolet rays and heat. This process can be reproduced artificially, maintaining specific temperature conditions in drying cabinets.

However, sludges stored for a long time have a significant advantage - they are the most stable by all measures. These chemical transformations result from water evaporation, carbonization of calcium and magnesium hydroxides, as well as aging of amorphous iron and aluminum hydro-complexes.

A series of research by S. F. Korenkova, T. V. Sheina, I. V. Yakushin [16-19] prove that sludge actively participates on the separate phase and component boundary, forming materials of different chemical composition, bond types and phase structures, affecting technology parameters of the production, as well as the structure and properties of the materials formed. 


\section{Conclusions}

Bearing in mind the foregoing and absence of organic impurities in water softening sludges and CSP, these wastes can be categorized as finished poly-structural mineral materials that can act as micro-structural elements with their physical and chemical properties as part of multi-layer facade compositions.

Application of CSP and sludge wastes in the production of facade plaster compositions allows to complement the raw-material resource base of the construction industry with a valuable nanotechnological raw material, and facilitates significant environmental measures aimed to reduce deposition on open plots of land allocated for landfills and waste burial sites. At the modern stage of development and improvement of the production of structural construction material for facade compositions in Russia, increasing the economic feasibility, solution of environmental issues, issues of resource conservation and durability of the coatings are possible through the use of secondary natural resources, i.e. finished nano-products of industrial production - flue dust from asphalt concrete plants (ACP) and water softening products (CS) from thermal power plants.

\section{References}

1. S.F. Korenkova, A.S. Mironova, The patent of the Russia No 2460710 (2012)

2. S.F. Korenkova, A.S. Mironova, The patent of the Russia No 2447037 (2012)

3. S. F. Korenkova, A. S. Mironova, The patent of the Russia No 2470891 (2012)

4. A. S. Mironova, The patent of the Russian Federation № 2470902 (2012)

5. S. F. Korenkova, A. S. Mironova, The patent of the Russia № 2373168 (2009)

6. K.T. Soltambekov, V.M. Bondareva, U.K. Makhambetova, Z.A. Yestemisov, Construction Materials, 4, 6-8 (2001)

7. B.V. Detyagin, N.A. Krotova, Adhesion (Academy of Sciences of the USSR, 1999)

8. V.I. Solomatov, V.P. Selyaev, Y.A. Sokolova, Chemical Resistance of Materials (Moscow, Russian Academy of Architecture and Construction Sciences, 1996)

9. V.I. Roldugin, Physics and Chemistry of the Surface (Dolgoprudny, Intellect, 2008)

10. Y.M. Bazhenov, Concrete polymer (Moscow, Stroyizdat, 1983)

11. A.A. Shentyapin, Modern Finishing Construction Materials (Samara, SAAC, 2000)

12. S.F. Korenkova, A.S. Mironova, Construction Materials, Equipment, Technologies of the 21st Century, 10(117), 60-61 (2008)

13. A.S. Mironova, Construction Materials, Equipment, Technologies of the 21st Century, 1(120), 58-59 (2009)

14. N.A. Lekareva, Urban Construction and Architecture, 1, 6-9 (2011)

15. K.L. Chertes, O.V. Tupicyna, V.N. Pystin, A.M. Shterenberg, Urban Construction and Architecture, 4, 78-84 (2015)

16. S.F. Korenkova, T.V. Sheina, Basics and Concepts of Disposal of Chemical Sediments of Industrial Wastewater in the Construction Industry, (Samara, SUACE, 2004)

17. S.F. Korenkova, I.V. Yakushin, Concrete Technology, 4, 62-64 (2007)

18. A.S. Mironova, S.F. Korenkova, Nanotechnologies in Construction, 2(6), 32-42 (2010)

19. A.S. Pershina, S.F. Korenkova, Nanotechnologies in Construction, 4(14), 36-46 (2011) 